\title{
REDD+, Conservation, and Conversion
}

\author{
Sudarsono Soedomo \\ Department of Forest Management, Faculty of Forestry, Bogor Agricultural University, Academic Ring Road, Campus IPB \\ Dramaga, PO Box 168, Bogor, Indonesia 16680
}

Received November 11, 2018 /Accepted December 28, 2018

\begin{abstract}
The effectiveness of periodical payment for forested lands as an incentive system to stop a conversion of forested lands is analyzed. Four simple models are outlined and analyzed to investigate behavior of the land manager whether to maintain the lands remain forested or to convert them to other uses. The analysis is pure theoretical employing the optimal con-trol theory. A key element to induce the land manager to adopt forest conservation rather than forest conversion is a combination of periodical payments for the forested lands and the desirable scrap value. Without the desirable scrap value, periodical payments of carbon stock, regardless of the tariff, cannot stop the conversion; the tariff affects only the time when the conversion will be conducted but it is not sufficient to induce the land manager not to convert the forested lands. On the basis of this analysis, then policy implication is outlined. In order to provide the desirable scrap value, then a policy change is required. However, its implementation very likely encounters serious challenges from the land manager.
\end{abstract}

Keywords: periodical payments, scrap value, conversion, forested land, optimal control

*Correspondenceauthor, email: ssoedomo@apps.ipb.ac.id

\section{Introduction}

The aim of REDD+ is to encourage developing countries to contribute to climate change mitigation efforts by: i) reducing greenhouse gas emissions (GHG) by slowing, halting and reversing forest loss and degradation; and ii) increasing removal of GHGs from the earth's atmosphere through the conservation, management and ex-pansion of forests. ${ }^{1}$ I have a problem with this kind of approach because once a forest has achieved its maximum stock the land on which the forest grows becomes a warehouse for merely storing carbon. Whereas there are so many places that practically cannot produce biomass at all, such as desert (Table 1). These kind of places are more suitable for warehousing the global carbon stock, while the tropical forests are more suitable for producing biomass containing the carbon. In order for the tropical forests to keep on producing the biomass, the forests must be harvested regularly instead of being kept at their maximum carbon stock. Conversely, preventing the tropical forests from being touched could be wasting the most productive ma- chine for capturing carbon.

Unfortunately, conserving the tropical forests is very complicated. Most tropical forests are located in developing countries, such Brazil, Congo, and Indonesia, where economically majority of the people relies on land-based activities for their livelihood. Forest degradation and deforestation are very rampant. Recently, oil palm plantation have frequently been blamed as a major driver of tropical deforestation (Busch et al. 2015; Carlson et al. 2018; Fitzherbert et al. 2008; Tata et al. 2014; Vijay et al. 2016;
Wilcove \& Koh 2010). However, it would be wiser to look at the forest itself rather than to blame other land uses, such as oil palm plantation, if they are more profitable economically. Even more ridiculous, there are educated groups of people who care more about orangutans than real people.

In 2005, The United Nations Framework on Climate Change (UNFCCC) agreed tostart a work program to explore a range of policy approaches and positive incentives for Reducing Emissions from Deforestation and Degradation (REDD) (Corbera et al. 2010). Since then the climate change discussions have infused the forest arena withnew enthusiasm through developing the instrument of reducing emissions from deforestation and Forest degradation and conservation, sustainable use and enhancement of forest carbon stocks, which are collectively known as REDD+ (Agrawal et al. 2011). As new international conservation and development programs, early stage of REDD + was welcomed and characterized by large amounts of resources and at- tention, along with high expectations of success that are rarely fulfilled (Massarella et al. 2018), including what happened in Indonesia.

The objective of writing this paper is to show theoretically the effectiveness ofcarbon credits in stopping the conversion of forested lands for alternative uses. The carbon credits meant in this paper are periodical payment for the forested land and final payment for the remaining forested land at the end of the contract. Certainly, this scheme of the payments may be considered as one form of REDD+. In this paper, I would like to signify that a periodical payment for forested lands is not sufficient to stop forest 
Table 1 Primary productivity

\begin{tabular}{lcc}
\hline \multicolumn{1}{c}{ Ecosystem } & $\begin{array}{c}\text { Net Aboveground Primary } \\
\text { Production }\left(\mathrm{kJ} \mathrm{m}^{2} \mathrm{yr}^{-1}\right)\end{array}$ & $\begin{array}{c}\text { Biomass } \\
\left(\mathrm{kJ} \mathrm{m}^{2}\right)\end{array}$ \\
\hline Desert & 1,686 & 4 \\
Tundra & 1,075 & 2 \\
Temperate grassland & 4,941 & 4 \\
Tropical grassland & 11,272 & 34 \\
Temperate forest & 21,055 & 5 \\
Tropical forest & 22,589 & 70 \\
\hline
\end{tabular}

conversion, regardless of the tariff paid. This periodical payment needs to be combined with the scrap value of the forested lands. In general, as suggested by Morel and Morel (2012), in order for carbon credits awarded for reducing emissions from deforestation and degradation of forests (REDD) to be effective, they need to be competitive with alternative land uses. Unfortunately, converting a hectare of forest for palm oil production will be more profitable to landowners than preserving it for carbon credits (Butler et al. 2009).

\section{Situation Scenario}

There are uniform $y_{0}$ units of land covered fully by natural forest. The land is owned by the state. To derive benefit from the land, the government transfers the land to a company to be utilized for whatever the company wants to do; the company is allowed to convert the land for alternative uses or to keep the land remains forested. The time period of the contract is T. In each period, the forested lands are given periodical payment as much as $w$ per unit per period. The discount rate employed is $r$. At the end of the contract, the land manager can sell the remaining forested lands for $\mathrm{S}(y$ (T), T).

If a conversion is chosen, the cost of the conversion is $c$ per unit that delivers the benefit of $p$ per unit. The conversion rate at period $t$ is $x(t)$ and the maximum conversion rate allowed is $x$ unit per period. The objective of the land manager is to maximize the net present value of the stream net benefits and the scrap value. We will investigate the behavior of the land manager in achieving this objective.

\section{Model Analysis}

In this section, four combinations between periodical payments and scrap value will be analyzed, namely without scrap value and without periodical payments, without scrap value with periodical payments, with scrap value and without periodical payments, and with scrap value and with periodical payments.

\subsection{Without Scrap Value}

The forested lands left over at the end of the concession period have no value. Intuitively, the land manager has no incentive to maintain the lands remain forested until the end of the concession period.

\subsubsection{Without Periodical Payment on the Forested Lands}

The problem of the land manager may be formulated as follows:

$$
\begin{aligned}
& \max _{x}\left\{\int_{0}^{T}[p x(t)-c x(t)] e^{-r t} \mathrm{~d} t\right\} \\
& \frac{\mathrm{d} y}{\mathrm{~d} t}=-x \\
& y(0)=y_{0} \text { and } y(\mathrm{~T}) \text { free }
\end{aligned}
$$

Hamiltonian of this problem is:

$\mathrm{H}=[p x(t)-c x(t)]-\lambda(t) x(t)$

where $\lambda(t)$ is the costate variable.

Since the Hamiltonian is linear in the control variable $x(t)$, then we have a bang- bang solution as follows:

$$
x(t)^{*}=\left\{\begin{array}{l}
x \text { if } \mathrm{p}>\mathrm{c}+\lambda(\mathrm{t}) \\
\propto \subset 0 \text { if } \mathrm{p} \leq \mathrm{c}+\lambda(\mathrm{t})
\end{array}\right.
$$

It indicates that the optimal conversion rate $x(t)^{*}$ is dependent on the costate vari-able $\lambda(t)$. Our task now is to find out the motion of the costate variable. The derivative of the Equation [4] with respect to $y(t)$ is

$-\frac{\partial H}{\partial y}+r \lambda(t)=\frac{\mathrm{d} \lambda}{\mathrm{d} t}$

Since the Hamiltonian has no state variable, then the solution for Equation [6] is:

$\lambda(t)=\lambda_{0} e^{r t}$

where $\lambda(0)=\lambda_{0}$.

Since the transversality condition is $\lambda(T)=0$, then $\lambda_{0}=$ 0 implying that $\lambda(t)=0$ for all $t$. The Equation (5) may be simplified as

$$
x(t)^{*}= \begin{cases}\bar{x} \text { if } & \mathrm{p}>\mathrm{c} \\ \infty & \end{cases}
$$

If $p>c$, then the conversion occurs since very beginning. On the contrary, if $p<c$, then the conversion will never be conducted.

\subsubsection{With Periodical Payment on the Forested Lands}

Let us assume that each unit of natural forest intact is awarded by $w$. The prob- lem of the forest manager becomes

$$
\begin{aligned}
& \max _{x}\left\{\int_{0}^{T}[p x(t)-c x(t)+w y(t)] e^{-r t} \mathrm{~d} t\right\} \\
& \frac{\mathrm{d} y}{\mathrm{~d} t}=-x(t) \\
& y(0)=y_{0} \quad \text { and } \quad y(\mathrm{~T}) \quad \text { free }
\end{aligned}
$$

Hamiltionian for this problem is as follows:

$$
\mathrm{H}=[p x(t)-c x(t)]+w y(t)]-\lambda(t) x(t)
$$

Bang-bang solution:

$$
x(t)^{*}=\left\{\begin{array}{l}
\bar{x} \text { if } \mathrm{p}>\mathrm{c}+\lambda \\
\varnothing 00 \text { if } \mathrm{p} \leq \mathrm{c}+\lambda
\end{array}\right.
$$

The motion of the costate variable is governed by the following Equation

$$
-\frac{\partial H}{\partial y}+r \lambda(t)=\frac{\mathrm{d} \lambda}{\mathrm{d} t} \Rightarrow-w+r \lambda(t)=\frac{\mathrm{d} \lambda}{\mathrm{d} t}
$$




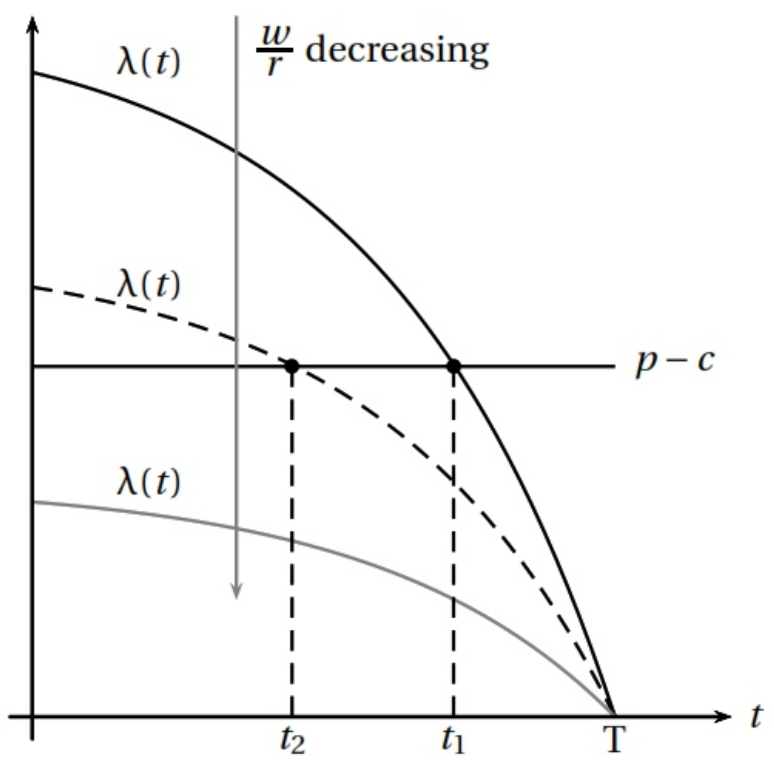

Figure 1 Timing of the conversion.

The general solution to this equation is

$$
\lambda(t)=\frac{w}{r}+k e^{r t}
$$

where: $k$ is a constant that needs to be determined to find out the definite solution. Since the transversality condition is $\lambda(\mathrm{T})=0$, then $k=-\frac{w}{r} e^{r T}$ as a result the definite solution for $\lambda(t)$.

$\lambda(t)=-\frac{w}{r}\left[1-e^{r(T-t)}\right]$

The $\frac{w}{r}$ determines the path level of $\lambda(t)$. For a given $r$, the smaller the $w$, the lower the $\lambda(t)$. Figure 1 presents the $\lambda(t)$ path for different level of $\frac{w}{r}$. If $p-c \geq \lambda(t)$ for all $t$, then the conversion occurs since very beginning. However, if $p-c<\lambda(t)$ for some $t$ and $p-c \geq \lambda(t)$ for some other $t$, then the conversion timing will be delayed but the conversion itself cannot be avoided. The conversion will occur when the shadow price curve of the natural forest intact crosses the $p-c$ curve from above.

The path of the forested land stock is dependent on the maximum conversion rate allowed. If the maximum conversion rate is very high, then the natural forests will be liquidated totally before $\mathrm{T}$. If the maximum conversion rate is too low, however, then the natural forests will not be liquidated fully at time $\mathrm{T}$.

\subsection{With Scrap Value}

The forested lands left over at the end of the concession period have a value. The value should be sufficient to induce the land manager to adopt a conservation strat- egy rather than a conversion strategy. Intuitively, the land manager has the incentive to maintain the lands remain forested until the end of the concession period if the scrap value is desired. Let $\mathrm{S}(y, \mathrm{~T})$ denote the salvage value of the natural forests at the end of the contract.

\subsubsection{Without periodical payment on the forested} lands

The objective of the land manager is

$\max _{x}\left\{\int_{0}^{T}[p x(t)-c x(t)] e^{-r t} d t+e^{-r t} \mathrm{~S}(\mathrm{y}(\mathrm{T}), \mathrm{T})\right\}$

with constraints

$\frac{\mathrm{d} y}{\mathrm{~d} t}=-x(t)$

$y(0)=y_{0} \quad$ and $\quad y(\mathrm{~T}) \quad$ free

Hamiltonian of this problem is

$\mathrm{H}=[p x(t)-c x(t)]-\lambda(t) x(t)$

This case has a similar solution for the control variable as the first case (Equation [5]). In addition, the general solution for the costate variable is also similar as shown in Equation [7]. To establish the definite solution for the costate variable, however, we have to rely on a different transversality condition. The transversality condition required here is $\lambda(\mathrm{T})=e^{-r T} \frac{\partial S}{\partial y} \mid y=y(T)$ (Sethi \& Thompson 2000). Asuming that $\mathrm{S}(y, t)=\phi y(\mathrm{~T})$, then $\lambda(\mathrm{T})$ $=e^{-r \mathrm{~T}} \phi$. Furthermore, the definite solution for the shadow price of the natural forest is

$$
\lambda(t)=\psi e^{-r(2 T-t)}
$$

Taking a derivative of Equation (21) with respect to $t$ yields

$\frac{\mathrm{d} \lambda(t)}{\mathrm{d} t}=\psi r e^{-r(2 T-t)}>0$

$\lambda(t)$ It indicates that Equation [21] is increasing in $t$ (Figure 2). Moreover, if $\phi \leq p-c$, then the conversion occurs since very beginning due to $\lambda(t)<(p-c)$ for $t<\mathrm{T}$. Two interesting cases may emerge when $\phi>p-c$, namely $\lambda(t)$ that never cross $p-c$ for all $t$ (the top curve), which is very unlikely to materialize, and $\lambda(t)$ that crosses $p-c$ at a particular $t$, say $t_{1}$ (the middle curve). In the first case, the conversion never occur, while in the second case, the conversion is initially done but finally stopped at $t_{1}$ when $\lambda\left(t_{1}\right)=p-c$.

\subsubsection{With periodical payment on the forested lands}

This is the last combination analyzed in this paper. The problem of the land manager may be formulated as follows:

$$
\begin{aligned}
& \max _{x}\left\{\int_{0}^{T}[p x(t)-c x(t)+w y(t)] e^{-r t} d t+e^{-r T} \mathrm{~S}(\mathrm{y}(\mathrm{T}), \mathrm{T})\right\} \\
& y=-x \\
& y(0)=y_{0} \text { and } y(\mathrm{~T}) \text { free }
\end{aligned}
$$

Hamiltonian of this problem is

$\mathrm{H}=[p x(t)-c x(t)+w y(t)]-\lambda(t) x(t)$ 
Due to linearity of the Hamiltonian in the control variable, then we have bang-bang

solution:

$$
x(t)^{*}=\left\{\begin{array}{l}
\bar{x} \text { if } \mathrm{p}>\mathrm{c}+\lambda \\
\propto \propto 0 \text { if } \mathrm{p} \leq \mathrm{c}+\lambda
\end{array}\right.
$$

As in Section 3.1.2, here we have the same form of the costate variable $\lambda(t)=\frac{w}{r}+k e^{r t}$. To establish the definitive solution for $\lambda(t)$, we have to figure out the value of the constant $k$ by employing the transversality condition

$$
\text { which is } \lambda(\mathrm{T})=e^{-r \mathrm{~T}} \phi \text { as in Section 3.2.1. So, we obtain: }
$$

The first term of the right side of this equation is the same as Equation [16], which is negative sloping in $t$, while the second term is the same as Equation [21], which has a positive slope. The slope of Equation [28] is certainly dependent on which one of the two terms is stronger or weaker. Taking a derivative of Equation [28] with respect to $t$ yields:

$$
\lambda(\mathrm{T})=\left.e^{-r T} \frac{\partial S}{\partial y}\right|_{y=y(T)}
$$

We know that $e^{-r(2 \mathrm{~T}-t)}<e^{-r(\mathrm{~T}-t)}$ for all $t$, while $r$ is less than 1. Hence, for $\phi$ that is close to $w$, Equation (29) will be negative. Theoretically, it can be positive if $\phi$ is away bigger than $w$, which is not realistic in the real world. For practical reason, therefore, I assume that Equation [29] is negative. In other words, Equation [28] is downward sloping in $t$ as long as $\phi$ is close to $w$.

Figure 3 presents three levels of scrap value. The bottom curve represents no scrap value and the conversion occurs at $t_{1}$ as previously obtained. The middle curve indicates periodical payment complemented with insufficient scrap value, so that the conversion still occur although it is little bit delayed to $t_{2}$. Finally, the top curve shows periodical payment complemented with sufficient scrap value, so that the conversion does not occur

\section{Discussion and Policy Implication}

The conversion does not occur so long the shadow price of the forested land, $\lambda(t)$, is higher than the net benefit from

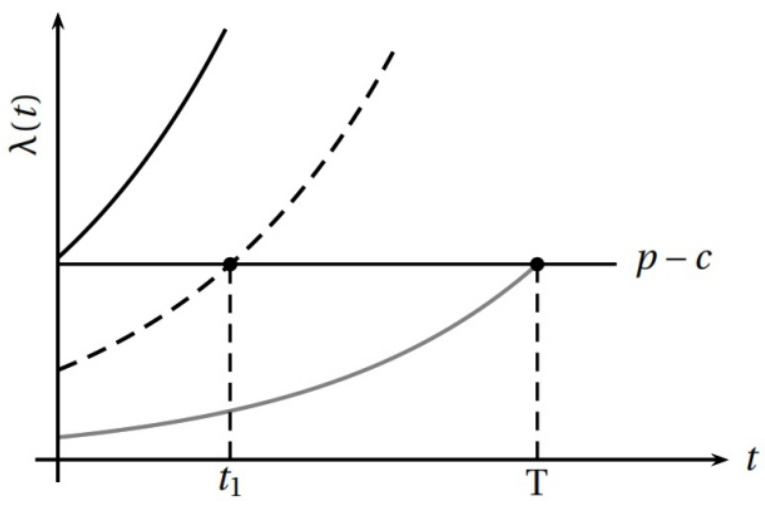

Figure 2 Relationship between unit scrap value and conversion timing. converting the land, $(p-c)$. When the shadow price of the forested land crosses the net benefit from the conversion, then the conversion starts realizing until the contract ends. The periodical payments can postpone the starting point of the conversion but cannot eliminate completely the possibility of the conversion itself regardless of the tariff (Figure 1). Meanwhile, scrap value is theoretically able to eliminate completely the possibility of the conversion, but the value required is unrealistically too high (Figure 2). Hence, the most probable approach to eliminating totally the possibility of the conversion with more realistic scrap value is a combination between the periodical payments and scrap value (Figure 3). Certainly, it is not an easy task to accomplish.

The meaning of the conversion may be relaxed to include any exploitation of the forested lands such that the forest stock does not meet the minimum stock required to obtain the periodical payments as well as to have scrap value. This relaxation allows us to analyze the behavior of the forest concession holders and certainly makes the model more realistic in reflecting the real world. Until today, the concession holders are facing uncertainty regarding the renewal of their concession. As consequence, the concession holders are reluctant to make long term investments to improve the stock of the forest under their concession. A salvage value to some degree is able to lessen the effect of uncertainties regarding the permit renewal. Scrap value can provide incentives for the concession holders to apply their creativity and capacity in improving the forested lands they manage. To adopt scrap value, however, the government needs to change the policies related to land concession.

The model shows that five parameters are involved in determining the possibility of the conversion, namely $p, c, r$ ,$w$, and $\phi$. Parameter $p$ dan $w$ have a conflicting effect on the conservation or conversion (Fisher et al.2014). Girma et al. (2012) shows that optimal forest stock is inversely related to the discount rate and at discount rates higher than $5 \%$, complete deforestation becomes the optimal land use choice. Moreover, as representation of $w$, (Rossi et al. 2017) suggests that carbon market prices are too low to be an incentive to change logging practices toward more climatesmart forest management, and a change of paradigm to

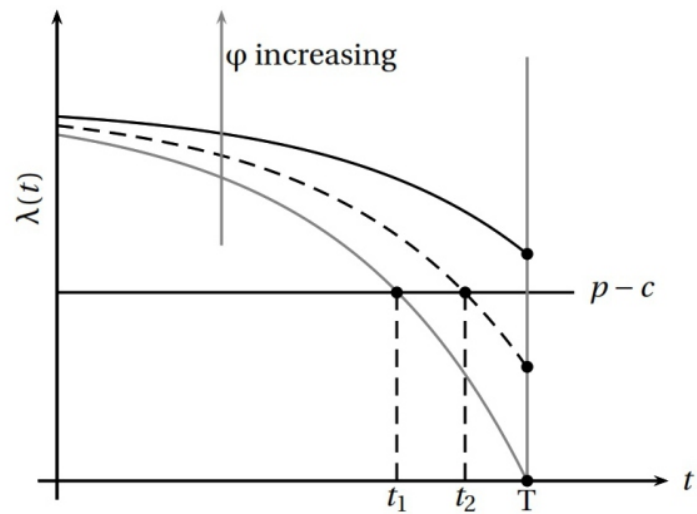

Figure 3 Conversion timing (above) and dynamics of the natural forest intact (bottom) 
change actors' behaviors would be needed. In addition, using contingent evaluation in Vietnam, Nielsen et al. (2018) shows that Willing To Accept (WTA) compensation for entering into contracts requiring farmers to refrain from cutting indigenous hardwood trees is 387-594 USD ha' ${ }^{-1}$ year

In the case of Indonesian natural forest utilization, the implementation of the scrap value of natural forest concession must be preceded by adjustment in the licensing tariff and enforcement of the performance guarantee fund that is mandated in the Law 41 of 1999. It would be extremely ridiculous when the concession holders can have scrap value at the end of the contract while they have paid very low for the concessionary areas and have not put any deposit as the performance guarantee. Meanwhile, the periodical payments potentially reduce the harvest rate of timber that determines the revenue of the government. By and large, the implementation of the periodical payments for forested lands and scrap value requires changes in policy. In short, I believe that the conversion of forested lands is very likely and very hard to stop. However, hopes do not totally go away (Aziz et al. 2015; Persson 2012; Rakatama et al. 2018; Strassburg et al.2009).

\section{Conclusion}

A conversion of forested land to alternative uses will not occur as long as the shadow price of the forested land is higher than the net benefit from the conversion. Periodical payments alone without scrap value will not be able to eliminate totally the possibilities of the conversion. Scrap value alone is theoretically can provide an incentive for keeping lands remain forested but the magnitude will be unrealistically too high. A combination of periodical payments and scrap value provide the most probable opportunity for totally avoiding conversion of forested lands. However, it is not a sufficient combination since the magnitude of the payments and scrap value matters.

\section{References}

Agrawal A, Nepstad D, Chhatre A. 2011. Reducing emissions from deforestation and forest degradation. Annual Review of Environment and Resources 36:373-396. https://doi.org/10.1146/annurev-environ042009-094508.

Aziz AA, Dargusch P, Phinn S, Ward A. 2015. Using redd+ to balance timber production with conservation objectives in a mangrove forest in malaysia. Ecological Economics 120:108-116.

Busch J, Ferretti-Gallon K, Engelmann J, Wright M, Austin KG, Stolle F, Turubanova S, Potapov PV, Margono B, Hansen MC, Baccini A. 2015. Reductions in emissions from deforestation from Indonesia's moratorium on new oil palm, timber, and logging concessions. Proceedings of the National Academy of Sciences, 112:1328-1333. https://doi.org/10.1073/pnas.1412514112.

Butler RA, Koh LP, Ghazoul J. 2009. REDD in the red: Palm oil could under- mine carbon payment schemes. Conservation Letters 2:67-73. https://doi.org/10.1111/
j.1755-263X.2009.00047.x.

Carlson KM, Heilmayr R, Gibbs HK, Noojipady P, Burns DN, Morton DC, Walker NF, Paoli GD, Kremen C. 2018. Effect of oil palm sustainability certification on deforestation and fire in Indonesia. Proceedings of the National Academy of Sciences 115(1):121-126. https://doi.org/10.1073/pnas.1704728114.

McNaughton SJ, Oesterheld M, Frank DA, Williams KJ. 1991. Primary and Secondary Production in Terrestrial Ecosystems. In: Comparative Analyses of Ecosystems. Cole J, Lovett G, Findlay S, editors. New York: Springer. https://doi.org/10.1007/978-1-4612-3122-6 7.

Corbera E, Estrada M, Brown K. 2010. Reducing greenhouse gas emissions from deforestation and forest degradation in developing countries: Revisiting the assumptions. Climatic Change 100(3-4):355-388. https://doi.org/ 10.1007/s10584-009-9773-1.

Fisher B, Edwards DP, Wilcove DS. 2014. Logging and conservation: Economic impacts of the stocking rates and prices of commercial timber species. Forest Policy and Economics 38:65-71. https://doi.org/10.1016/j.forpol. 2013.05.006.

Fitzherbert EB, Struebig MJ, Morel A, Danielsen F, Brühl, CA, Donald PF, Phalan, B. 2008. How will oil palm expansion affect biodiversity? Trends in Ecology \& Evolution 23(10):538-545. https://doi.org/10.1016/ j.tree.2008.06.012.

Girma HM, Hassan RM, Hertzler G. 2012. Forest conservation versus con version under uncertain market and environmental forest benefits in Ethiopia: The case of Sheka forest. Forest Policy and Economics 21:101-107. https://doi.org/10.1016/j.forpol.2012.01.001.

Massarella K, Sallu SM, Ensor JE, Marchant R. 2018. REDD+, hype, hope and disappointment: The dynamics of expectations in conservation and development pilot projects. World Development 109:375-385. https://doi.org/10.1016/j.worlddev.2018.05.006.

Morel AC, Morel BF. 2012. How could carbon credits for reducing defor- estation compete with returns from palm oil: A proposal for a more flexible redd valuation tool. Journal of Sustainable Forestry 31:11-28. https://doi.org/10.1080/10549811.2011.565709.

Nielsen MR, Theilade I, Meilby H, Nui NH, Lam NT. 2018. Can PES and REDD+ match Willingness to Accept payments in contracts for reforestation and avoided forest degradation? The case of farmers in upland Bac Kan, Vietnam. Land Use Policy 79:822-833. https://doi.org/10.1016/j.landusepol.2018.09.010.

Persson UM. 2012. Conserve or convert? pantropical modeling of REDD-bioenergy competition. Biological Conservation 146(1):81-88. https://doi.org/10.1016/ j.biocon.2011.10.038. 
Rakatama A, Pandit R, Iftekhar S, Ma C. 2018. How to design more effective REDD+ projects-The importance of targeted approach in Indonesia. Journal of Forest Economics 33:25-32. https://doi.org/10.1016/ j.jfe.2018.10.003.

Rossi V, Claeys F, Bastin D, Gourlet-Fleury S, Guizol P, Eba'a-Atyi R, Sonwa DJ, Lescuyer G, Picard N. 2017. Could REDD+ mechanisms induce log-ging companies to reduce forest degradation in Central Africa? Journal of Forest Economics 29:107-117. https://doi.org/ 10.1016/j.jfe.2017.10.001.

Sethi S, Thompson GL. 2000. Optimal Control Theory. New York: Springer.

Strassburg B, Turner RK, Fisher B, Schaeffer R, Lovett A. 2009. Reducing emissions from deforestation. The "combined incentives" mechanism and empirical simulations. Global Environmental Change
19(2):265-278. https://doi.org/10.1016/j.gloenvcha. 2008.11.004.

Tata HL, Noordwijk M, Ruysschaert D, Mulia R, Rahayu S, Mulyoutami E, Widayati A, Ekadinata A, Zen R, Darsoyo A, Oktaviani R, Dewi S. 2014. Will funding to reduce emissions from deforestation and (forest) degradation (REDD+) stop conversion of peat swamps to oil palm in orangutan habitat in tripa in Aceh, Indonesia? Mitigation and Adaptation Strategies for Global Change 19:693-713.

Vijay V, Pimm SL, Jenkins CN, Smith SJ. 2016. The impacts of oil palm on recent deforestation and biodiversity loss. PloS one 11(7):e0159668. https://doi.org/10.1371/ journal.pone. 0159668 .

Wilcove DS, Koh LP. 2010. Addressing the threats to biodiversity from oil- palm agriculture. Biodiversity and Conservation 19(4):999-1007. https://doi.org/ 10.1007/s10531-009-9760-x 